\title{
Expression of genes and proteins of multidrug resistance in gastric cancer cells treated with resveratrol
}

\author{
KATARZYNA MIESZALA ${ }^{1,2}$, MALGORZATA RUDEWICZ ${ }^{1,2}$, AGNIESZKA GOMULKIEWICZ ${ }^{1}$, \\ KATARZYNA RATAJCZAK-WIELGOMAS ${ }^{1}$, JEDRZEJ GRZEGRZOLKA ${ }^{1}$, \\ PIOTR DZIEGIEL ${ }^{1,3}$ and SYLWIA BORSKA ${ }^{1}$ \\ ${ }^{1}$ Department of Histology and Embryology, Wroclaw Medical University, 50-368 Wroclaw; \\ ${ }^{2}$ Faculty of Chemistry, Wroclaw University of Science and Technology, 50-373 Wroclaw; ${ }^{3}$ Department of \\ Physiotherapy, Wroclaw University School of Physical Education, 51-612 Wroclaw, Poland
}

Received July 4, 2017; Accepted November 16, 2017

DOI: $10.3892 / \mathrm{ol} .2018 .8022$

\begin{abstract}
Multidrug resistance (MDR) is a notable problem in the use of chemotherapy. Therefore, studies aimed at identifying substances capable of overcoming resistance of cancer cells are required. Examples of these compounds are polyphenols, including resveratrol, that exert a range of various biological activities. The aim of the present study was to demonstrate the effect of 3,5,4'-trihydroxy-trans-stilbene (resveratrol) on the expression of ATP binding cassette subfamily B member 1, Annexin A1 (ANXA1) and thioredoxin $(T X N)$ genes, and the proteins encoded by these genes, which are associated with MDR. The experiments were performed in human gastric cancer cell lines EPG85-257RDB (RDB) and EPG85-257RNOV (RNOV), which are resistant to daunorubicin and mitoxantrone, respectively, in addition to EPG85-257P (control), which is sensitive to cytostatic drugs. Cells were treated with 30 or $50 \mu \mathrm{M}$ resveratrol for $72 \mathrm{~h}$ and changes in the expression levels of the genes were analysed with the use of a reverse transcription-quantitative polymerase chain reaction. The cellular levels of P-glycoprotein (P-gp), ANXA1 and TXN were evaluated using immunofluorescence and western blot analysis. Resveratrol in both concentrations has been shown to have a statistically significant influence on expression of the mentioned genes, compared with untreated cells. In RDB cells, resveratrol reduced the expression level
\end{abstract}

Correspondence to: Dr Sylwia Borska, Department of Histology and Embryology, Wroclaw Medical University, 6a Chalubinskiego, 50-368 Wroclaw, Poland

E-mail: sylwia.borska@umed.wroc.pl

Abbreviations: P, human gastric carcinoma EPG85-257P cell line; RDB, human gastric carcinoma EPG85-257RDB cell line; RNOV, human gastric carcinoma EPG85-257RNOV cell line; R30, $30 \mu \mathrm{M}$ resveratrol; P-gp, P-glycoprotein; GUSB, $\beta$-glucuronidase; POLR2A, RNA polymerase IIa

Key words: multidrug resistance, resveratrol, gastric cancer of all analyzed genes, compared with untreated cells. Similar results at the protein level were obtained for P-gp and TXN. In turn, in the RNOV cell line, resveratrol reduced TXN expression at mRNA and protein levels, compared with untreated cells. The results of the present study indicate that resveratrol may reduce the resistance of cancer cells by affecting the expression of a number of the genes and proteins associated with MDR.

\section{Introduction}

Resveratrol belongs to the stilbenoid group of polyphenols, possessing two phenol rings linked to each other by an ethylene bridge (1). In 1940, resveratrol was isolated from the root of Veratrum grandiflorum $(1,2)$. A primary dietary source of resveratrol is red wine, as a very high resveratrol concentration is present in the skin of red grapes (50-100 $\mu \mathrm{g} / \mathrm{g}$ ) (3). In natural conditions, resveratrol is synthesized by plants in response to external environmental factors, including ultraviolet radiation and heavy metals $(3,4)$. Resveratrol is identified in two isomeric forms, cis and trans-resveratrol (Fig. 1) (5,6).

The trans form is dominant in terms of its prevalence and biological activity (7). The hydrophobic nature of resveratrol considerably contributes to its limited bioavailability (8). Owing to the varied biological activity of resveratrol, it has been the subject of numerous studies aimed at revealing its health-enhancing properties, and its use in prevention and treatment of many diseases $(1,3,5,9)$. The results of in vitro and in vivo studies have proved that resveratrol exhibits anticancer activity at all three stages of the oncogenic process: initiation, promotion and progression (10).

Neoplastic diseases are presently one of the main causes of global mortality. One of the most commonly used cancer treatment methods is chemotherapy (11); however, its effectiveness is substantially reduced by multidrug resistance (MDR) (12-14). MDR is defined as the insensitivity to therapeutic substances that are not associated by structure or mechanism of action $(15,16)$. The classical mechanism of MDR is associated with the overexpression of the ATP binding cassette subfamily $\mathrm{B}$ member 1 ( $A B C B 1)$ gene encoding $\mathrm{P}$-glycoprotein ( $\mathrm{P}-\mathrm{gp})$, which contributes to the 
reduction of the effective drug concentration in the cell by transporting the drug out of the cell $(14,15,17-20)$. In addition to the classical MDR mechanism associated with overexpression of P-gp, there are atypical mechanisms (21-23). Examples of these atypical mechanisms include the overexpression of Annexin A1 (ANXA1) and thioredoxin (TXN) proteins. The ANXA1 gene encodes the ANXA1 protein, which reversibly binds $\mathrm{Ca}^{2+}$ ions and phospholipids of the plasma membrane (24). ANXA1 regulates cell growth, differentiation and apoptosis (25). Increased expression of ANXA1 contributes to the formation of drug-filled vesicles, which are then exocytosed (26). The TXN gene encodes a protein involved in the process of the regulation of cellular redox state. In cancer cells, increased TXN expression results in an increase in proliferation and cell survival (27). Resveratrol is an example of a natural compound with the ability to overcome resistance to chemotherapy. In vitro studies on the sensitisation of cells to daunorubicin (DB) with the use of resveratrol, in cases of leukaemia, pancreatic and prostate cancer, it was revealed that resveratrol increased the apoptosis of those cells (28). The aim of the present study was to evaluate the effect of resveratrol on the expression level of $A B C B 1, A N X A 1$ and $T X N$ genes, which are associated with the MDR phenomenon in DB- and mitoxantrone (MTX)-resistant human gastric cancer cells.

\section{Materials and methods}

Cell lines and culture conditions. In vitro studies were performed in three human gastric cancer cell lines that were either sensitive or resistant to cytostatic drugs. EPG85-257P (P) cell line is sensitive to DB and MTX, whereas EPG85-257RDB (RDB) and EPG85-257RNOV (RNOV) cell lines are resistant to DB and MTX, respectively. Cell lines were obtained from the Institute of Pathology, Charité Campus Mitte, Humboldt University (Berlin, Germany). Cells were cultured in $75 \mathrm{~cm}^{2}$ culture flasks (Thermo Fisher Scientific, Inc., Waltham, MA, USA). Leibovitz's medium L-15 (Sigma-Aldrich; Merck KGaA, Darmstadt, Germany), supplemented with $10 \%$ foetal bovine serum, $1 \mathrm{mM}$ L-glutamine, $6.25 \mathrm{mg} / 1$ fetuin, $80 \mathrm{IE} / 1$ insulin, $2.5 \mathrm{mg} / 1$ transferrin, $1 \mathrm{~g} / \mathrm{l}$ glucose, $1.1 \mathrm{~g} / 1 \mathrm{NaHCO}_{3}$ and $1 \%$ minimal essential vitamins (all from Sigma-Aldrich; Merck KGaA) was used to culture all cells. Adequate resveratrol (Sigma-Aldrich; Merck KGaA) was added to the medium to maintain resistance of the cells, $2.5 \mu \mathrm{g} / \mathrm{ml}$ DB (Sigma-Aldrich; Merck KGaA) for RDB and $0.02 \mu \mathrm{g} / \mathrm{ml}$ MTX (Sigma-Aldrich; Merck KGaA) for the RNOV cell line.

Reverse transcription-quantitative polymerase chain reaction $(R T-q P C R)$. Changes in the expression of $A B C B 1, A N X A 1$ and $T X N$ genes in $\mathrm{P}, \mathrm{RDB}$ and RNOV cell lines were evaluated following the use of resveratrol at concentrations of $30 \mu \mathrm{M}$ (R30) and $50 \mu \mathrm{M}$ (R50). Resveratrol concentrations were chosen based on cytotoxicity studies for this compound (29). After $72 \mathrm{~h}$ incubation at $37^{\circ} \mathrm{C}$ with resveratrol, the cells were trypsinized $\left(37^{\circ} \mathrm{C}\right.$ for $7 \mathrm{~min}$; Sigma-Aldrich; Merck KGaA) and the resulting residues were collected. RNeasy Mini kit (Qiagen GmbH, Hilden, Germany) was used for RNA isolation according to the manufacturer's protocol. To remove
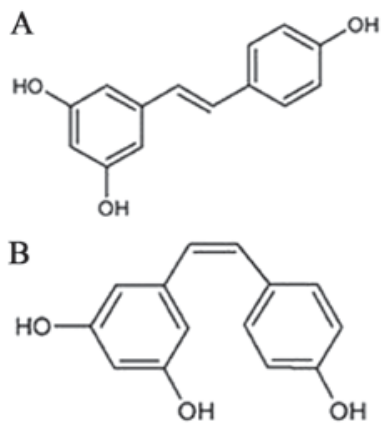

Figure 1. Structural formula of resveratrol isomeric forms. (A) Trans-resveratrol and (B) cis-resveratrol.

genomic DNA, samples were digested using the RNase-Free DNase Set (Qiagen $\mathrm{GmbH}$ ), according to the manufacturer's protocol. Next, reverse transcriptase was performed using the High-Capacity cDNA Reverse Transcription kits (Applied Biosystems; Thermo Fisher Scientific, Inc.), according to the manufacturer's protocol. Changes in gene expression were evaluated using RT-qPCR with the use of the 7900HT Fast Real Time PCR system, and SDS 2.3 and RQ Manager 1.2 software (Applied Biosystems; Thermo Fisher Scientific, Inc.). Glucuronidase- $\beta$ (GUSB) and RNA polymerase II subunit A (POLR2A) were used as reference genes. Relative expression of the genes in RDB and RNOV cells were assessed in comparison with the $\mathrm{P}$ cell line. The following sets of primers and TaqMan probes with FAM $^{\text {TM }}$ dye-labeled were used in the reactions: Hs00184500_m1 for $A B C B 1$, Hs00167549_m1 for ANXA1, Hs01555212_g1 for $T X N$, Hs99999908_m1 for GUSB and Hs00172187_m1 for POLR2A (Applied Biosystems; Thermo Fisher Scientific, Inc.). Thermocycling reactions were conducted in triplicate under the following conditions: polymerase activation at $50^{\circ} \mathrm{C}$ for 2 min, initial denaturation at $94^{\circ} \mathrm{C}$ for $10 \mathrm{~min}$, and 40 cycles of denaturation at $94^{\circ} \mathrm{C}$ for $15 \mathrm{sec}$ and annealing of the primers and probes and synthesis at $60^{\circ} \mathrm{C}$ for $1 \mathrm{~min}$. Relative gene expression was calculated using the $2^{-\Delta \Delta \mathrm{Cq}}$ method (30). Three experimental replicates were performed.

Western blot analysis. Total cellular proteins were isolated from each of the tested cell lines at $4^{\circ} \mathrm{C}$ for $10 \mathrm{~min}$, using $200 \mu \mathrm{l} / 3 \mathrm{mln}$ cells with radioimmunoprecipitation assay lysis buffer (50 mM Tris- $\mathrm{HCl} \mathrm{pH}$ 8.0, $150 \mathrm{mM} \mathrm{NaCl}, 0.1 \%$ SDS, $1 \%$ IGEPAL CA-630 and $0.5 \%$ sodium deoxycholate), $0.5 \mathrm{mM}$ phenylmethylsulfonyl fluoride and protease inhibitor cocktail $10 \mu \mathrm{l} / \mathrm{ml}$ RIPA. The samples were agitated for $30 \mathrm{~min}$ at $4^{\circ} \mathrm{C}$, and centrifuged $\left(4^{\circ} \mathrm{C}\right.$ for $12 \mathrm{~min}$ at $\left.12,000 \mathrm{x} \mathrm{g}\right)$ and the supernatant was collected. Protein concentration was determined using a bicinchoninic acid assay with the use of Pierce BCA Protein Assay kit (Thermo Fisher Scientific, Inc.). A suitable quantity of $4 \mathrm{X}$ Glo Lysis buffer (31) was added to the remaining supernatant and was denaturized at $95^{\circ} \mathrm{C}$ for $10 \mathrm{~min}$. Electrophoresis was performed by $10 \%$ SDS-PAGE at $140 \mathrm{~V}$. Total cellular proteins were visualized with the Chemi Doc MP (Bio-Rad Laboratories, Inc., Hercules, CA, USA) apparatus. A total of $30 \mu \mathrm{g}$ proteins (per lane) were transferred to polyvinylidene fluoride membrane (Immobilon-P; EMD Millipore, Billerica, MA, USA) in 
A

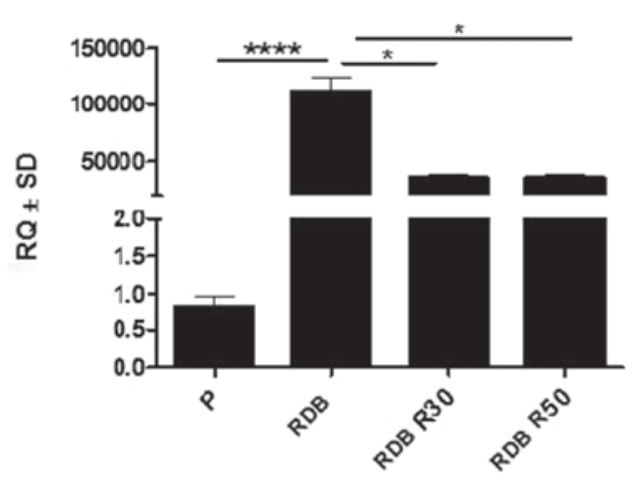

B

RDB: P-glyoprotein

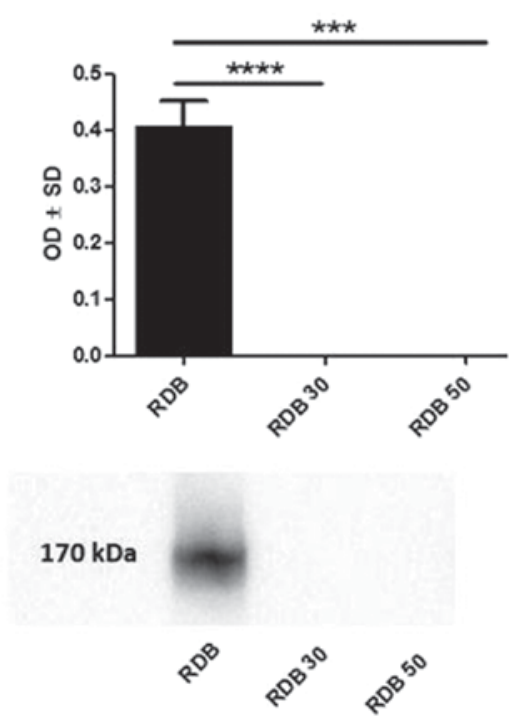

Figure 2. Effect of resveratrol on the levels of $A B C B 1$ and P-gp in a RDB cell line. Expression levels of (A) $A B C B 1$ gene and (B) P-gp protein in P and RDB cell lines. " $\mathrm{P}<0.05$ and ${ }^{* * * *} \mathrm{P}<0.0001$ with comparisons indicated by lines. $A B C B 1$, ATP binding cassette subfamily B member 1 ; P-gp, P-glycoprotein; P, EPG85-257P cell line; RDB, EPG85-257RDB cell line; R30, $30 \mu \mathrm{M}$ resveratrol; RQ, relative quantity; SD, standard deviation; OD, optical density.

transfer buffer (48 mM Tris, $39 \mathrm{mM}$ glycine, $20 \%$ methanol and $0.1 \%$ SDS, $\mathrm{pH} 9.2$ ) by constant current at $250 \mathrm{~mA}$ for $1 \mathrm{~h}$. Subsequent to washing the membranes in distilled water and $0.1 \%$ TBS-Tween-20 (TBST), they were blocked with 4\% BSA (Sigma-Aldrich; Merck KGaA) in $0.1 \%$ TBST (room temperature for $1 \mathrm{~h}$ ). Membranes were incubated with primary antibodies: Mouse anti-P-gp monoclonal antibody C219 (dilution 1:300; cat. no. ALX-801-002-C100; Enzo Life Sciences, Inc., Farmingsale, NY, USA), rabbit anti-ANXA1 polyclonal Ab H-65 (dilution 1:150; cat. no. sc-11387; Santa Cruz Biotechnology, Inc., Dallas, TX, US), rabbit anti-TXN monoclonal Ab (dilution 1:5,000; cat. no. LS-B7196; LifeSpan Biosciences, Inc., Seattle, WA, USA) at $4^{\circ} \mathrm{C}$ for $12 \mathrm{~h}$. Secondary anti-mouse and anti-rabbit antibodies were used at dilution of 1:3,000 at room temperature for $1 \mathrm{~h}$. $\left(\mathrm{Cy}^{\mathrm{TM}} 3\right.$ AffiniPure Donkey Anti-Rabbit IgG (H+L); cat. no. 711-025-152; and Peroxidase AffiniPure Donkey Anti-Mouse $\operatorname{IgG}(\mathrm{H}+\mathrm{L})$; cat. no. 715-025-150; Jackson ImmunoResearch Laboratories, Inc., West Grove, PA, USA). The measurements were taken with the Chemi Doc MP System apparatus, using Image Lab 5.0 Software (both from Bio-Rad Laboratories, Inc.). The level of protein expression was determined as the ratio between signal intensity for a given protein and signal intensity for total cellular proteins.

Immunofluorescence (IF). The cells for the IF reaction were cultured at a density of $1 \times 10^{4}$ cells/well for RDB and $8 \times 10^{3}$ cells/well for RNOV in 8-wells Milicell ${ }^{\circledR}$ EZ SLIDES (Sigma-Aldrich; Merck KGaA). Culturing was performed under the same conditions as for RT-qPCR. The cells were fixed in $4 \%$ paraformaldehyde for $12 \mathrm{~min}$ at room temperature. For membrane permeabilisation, $0.2 \%$ Triton X-100 was used (for $10 \mathrm{~min}$ at room temperature). The cells were incubated for $1 \mathrm{~h}$ at room temperature with the following primary antibodies: Mouse anti-P-gp monoclonal antibody
C219 (dilution 1:100; cat. no. ALX-801-002-C100; Enzo Life Sciences, Inc.), rabbit anti-ANXA1 polyclonal antibody H-65 (dilution 1:100; cat. no. sc-11387; Santa Cruz Biotechnology, Inc.) and rabbit anti-TXN monoclonal antibody (dilution 1:100; cat. no. LS-B7196; LifeSpan Biosciences, Inc.). Proteins were detected with [tetramethylrhodamine (TRITC)-conjugated AffiniPure ${ }^{\circledR}$ donkey anti-rabbit $\left.\operatorname{IgG}(\mathrm{H}+\mathrm{L})\right]$ and TRITC-conjugated AffiniPure ${ }^{\circledR}$ donkey anti-mouse $\operatorname{IgG}(\mathrm{H}+\mathrm{L})$ secondary antibodies (cat. nos. 711-025-152 and 715-025-150; Jackson's ImmunoResearch Laboratories, Inc.), at a dilution of 1:2,000 ( $1 \mathrm{~h}$ incubation at $\left.4^{\circ} \mathrm{C}\right)$. Preparations were mounted on DAPI-containing media (Prolong Gold Antifode Reagent with DAPI; Thermo Fisher Scientific, Inc.). The analysis of protein expression was conducted using a fluorescent microscope (Olympus BX41; Olympus Corporation, Tokyo, Japan) at x40 magnification.

Statistical analysis. Statistical analysis was performed using GraphPad Prism 5.0 software (GraphPad Software, Inc., La Jolla, CA, USA). One-way analysis of variance for ranks (Kruskal-Wallis test) was performed using post-hoc Dunn's or Bonferroni tests. Data were presented as the mean \pm standard deviation. $\mathrm{P}<0.05$ was considered to indicate a statistically significant difference.

\section{Results}

Effect of resveratrol on the level of expression of $A B C B 1$ gene and $P$-gp protein in an RDB cell line. The untreated DB-resistant RDB cell line significantly overexpressed the $A B C B 1$ gene when compared with the $\mathrm{P}$ cell line, which is DB-sensitive $(\mathrm{P}<0.0001$; Fig. 2A). The level of $A B C B 1$ gene expression was significantly reduced following the use of resveratrol at R30 concentration in comparison with expression in the untreated DB-resistant cell line $(\mathrm{P}<0.05)$. A similar 

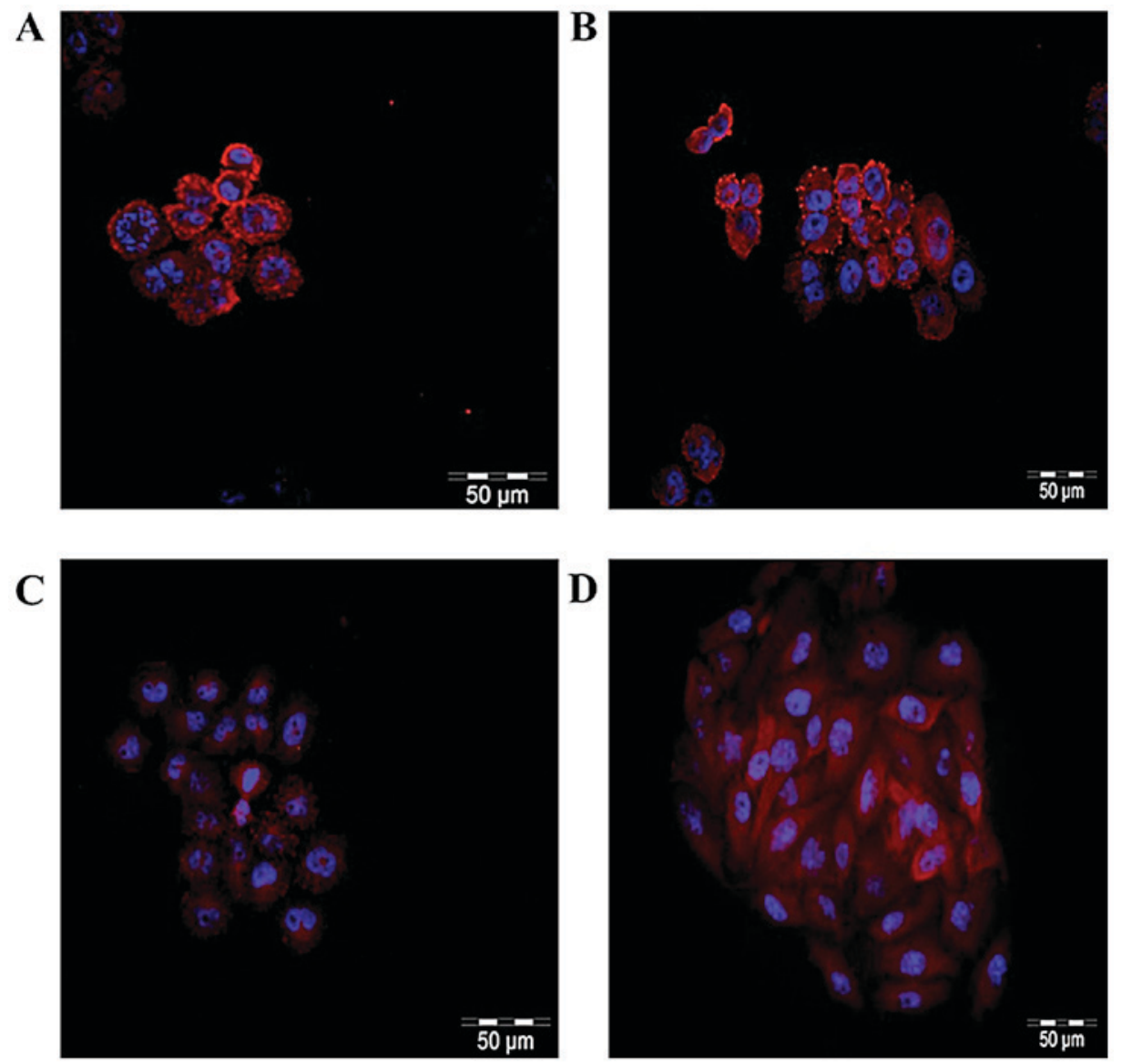

Figure 3. Immunofluorescence reactions confirming the presence of P-gp, ANXA1 and TXN in human gastric cancer cell lines. Presence of (A) membrane reaction, P-gp, primarily in the membrane; (B) ANXA1, primarily in the cytoplasm; (C) TXN, primarily in the cytoplasm, all in the EPG85-257RDB cell line; and (D) TXN, primarily in the cytoplasm in the EPG85-257RNOV cell line. P-gp, P-glycoprotein; SD, standard deviation; ANXA1, Annexin A1; TXN, thioredoxin.

association was revealed at the protein level with the use of western blot analysis. In the R30- and R50-treated groups, the protein level dropped below the quantitation level. Thus, there was a statistically significant difference between the two resveratrol-treated groups and the untreated group ( $\mathrm{P}<0.0001$; Fig. 2B).

The presence of individual proteins in cell lines was confirmed using IF. In the RDB cell line: P-gp (Fig. 3A); Annexin A1 (Fig. 3B); and thioredoxin (Fig. 3C), and in the RNOV cell line, thioredoxin (Fig. 3D).

Effect of resveratrol on the change of the expression of ANXA1 and TXN genes and proteins in the RDB cell line. It was revealed that in the RDB cell line, aside from the classical resistance mechanism ( $A B C B 1$ gene overexpression), other atypical mechanisms are present that are associated with an increased expression of $A N X A 1$ and $T X N$ genes Expression of the ANXA1 gene in RDB cells is significantly higher than that in $\mathrm{P}$ cells $(\mathrm{P}<0.0001$; Fig. $4 \mathrm{~A})$. R30 treatment resulted in the significant reduction of gene expression in the RDB cell line compared with the $\mathrm{P}$ cell line $(\mathrm{P}<0.001$; Fig. $4 \mathrm{~A})$. $\mathrm{R} 50$ treatment resulted in the additional decrease in the expression of this gene, significantly when compared with control RDB cells $(\mathrm{P}<0.001)$ and non-significantly compared with R30-treated RDB cells (Fig. 4A). On the protein level, an increase in the expression of ANXA1 with increasing resveratrol concentration was revealed; however, this difference was not statistically significant (Fig. 4B). However, with respect to the $T X N$ gene, significant overexpression was observed in the RDB cell line in comparison with the $\mathrm{P}$ cell line $(\mathrm{P}<0.001 ;$ Fig. 5A). Incubation with $\mathrm{R} 30$ resulted in the significant reduction of gene expression when compared with the control RDB cell line ( $\mathrm{P}<0.001$; Fig. 5A). Analysis of protein levels confirmed the results of RT-qPCR. Treating RDB cells with R30 resulted in a reduced level of protein expression when compared with RDB cells not treated with the polyphenol, with R50 resulting in the further reduction of TXN expression compared with non-treated cells and R30-treated cells (Fig. 5B).

Effect of resveratrol on the expression level of TXN $m R N A$ and protein in the RNOV cell line. The presence of atypical MDR mechanisms associated with the overexpression of $T X N$ was revealed in the RNOV cell line. Expression of this gene in the RNOV cell line was significantly higher in comparison with the $\mathrm{P}$ cell line $(\mathrm{P}<0.001$; Fig. $6 \mathrm{~A})$. R30 significantly reduced the level of gene expression in comparison with the untreated RNOV cell line ( $\mathrm{P}<0.0001$; Fig. 6A). The same results were obtained at the protein level: The difference in expression levels between TXN in untreated RNOV cells and R50-treated RNOV cells was statistically significant $(\mathrm{P}<0.05$; Fig. 6B). 
A

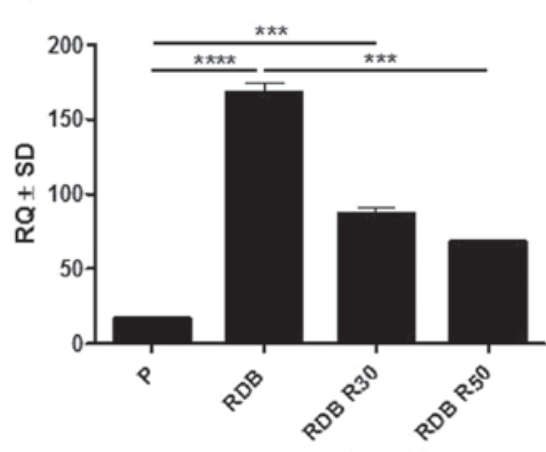

B

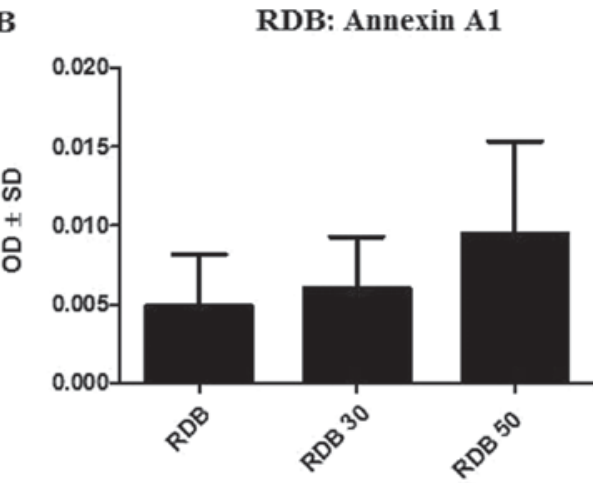

$37 \mathrm{kDa}$

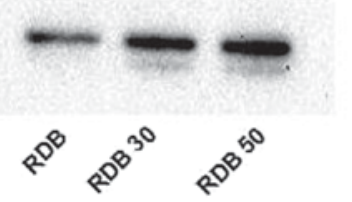

Figure 4. Effect of resveratrol on the expression levels of ANXA1 and ANXA1. Expression levels of (A) ANXA1 and (B) ANXA1 protein in P and RDB cell lines. ${ }^{* * *} \mathrm{P}<0.001$ and ${ }^{* * * *} \mathrm{P}<0.0001$, with comparisons shown by lines. R30, $30 \mu \mathrm{M}$ resveratrol concentration; R50, 50 $\mu \mathrm{M}$ resveratrol; P, EPG85-257P; RDB, EPG85-257RDB; ANXA1, Annexin A1; RQ, relative quantity; OD, optical density; SD, standard deviation.

A

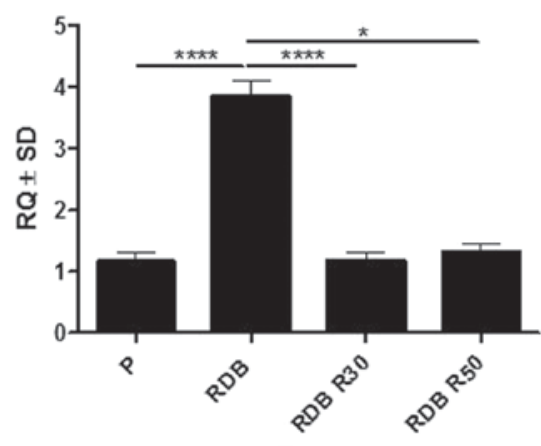

B

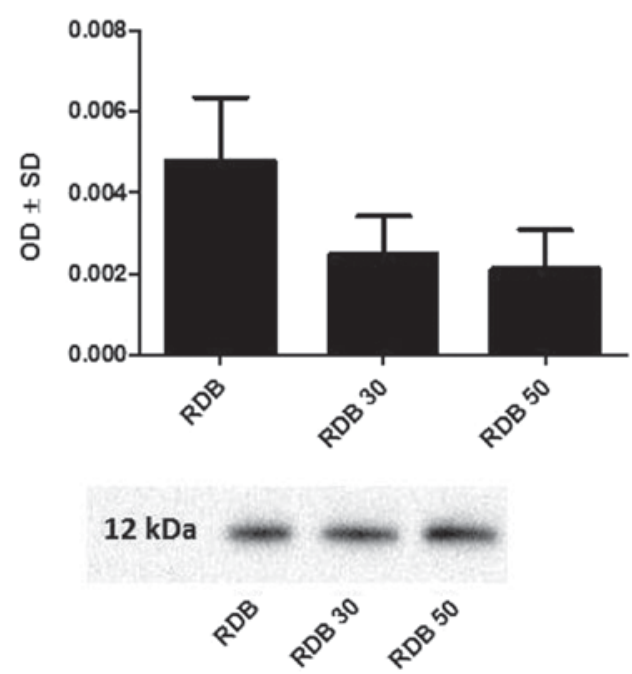

Figure 5. Effect of resveratrol on the expression levels of TXN and TXN in RDB cells. Expression levels of (A) TXN gene and (B) TXN protein in P and RDB cell lines. ${ }^{*} \mathrm{P}<0.05$ and ${ }^{* * * *} \mathrm{P}<0.0001$. R30, $30 \mu \mathrm{M}$ resveratrol concentration; R50, $50 \mu \mathrm{M}$ resveratrol; P, EPG85-257P; RDB, EPG85-257RDB; TXN, thioredoxin; $\mathrm{RQ}$, relative quantity; OD, optical density; SD, standard deviation.

\section{Discussion}

MDR is a notable problem for chemotherapy and results in a lower chemotherapeutic efficacy (32). Drug-resistance in cancer cells develops as a result of numerous different mechanisms, of which understanding has improved owing to the use of novel research techniques. These mechanisms include the lowering of the intracellular drug concentration, activation of detoxification enzymes, changes in drug metabolism inside of the cell and the inhibition of cancer cell apoptosis $(33,34)$. The most well-known and frequently described MDR mechanism is the increased expression of transport proteins at the membrane of cancer cells (35). Therefore, studies on substances that enable cancer cell sensitisation to cytostatics are necessary. Such compounds include polyphenols such as resveratrol, curcumin or quercetin $(19,36)$. The effects of polyphenol compounds were studied in human leukaemia cell lines sensitive (K562) and resistant (K562/A02) to DB. In this study, it was revealed that curcumin contributes to the reduction of cell viability and to DNA damage. The effect of curcumin on cancer cell apoptosis was also reported (37). Resveratrol and its ability to overcome MDR were studied in pancreatic cancer cell lines EPP85-181 that were sensitive or resistant to cytostatics, in which the low level of type II topoisomerase expression was one of the causes of resistance. Resveratrol increased the expression of type II topoisomerse and therefore enhanced cells sensitivity to antracyclines (36). 
A

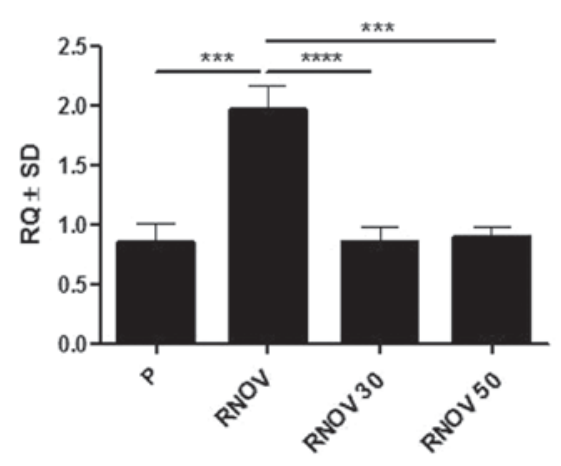

B

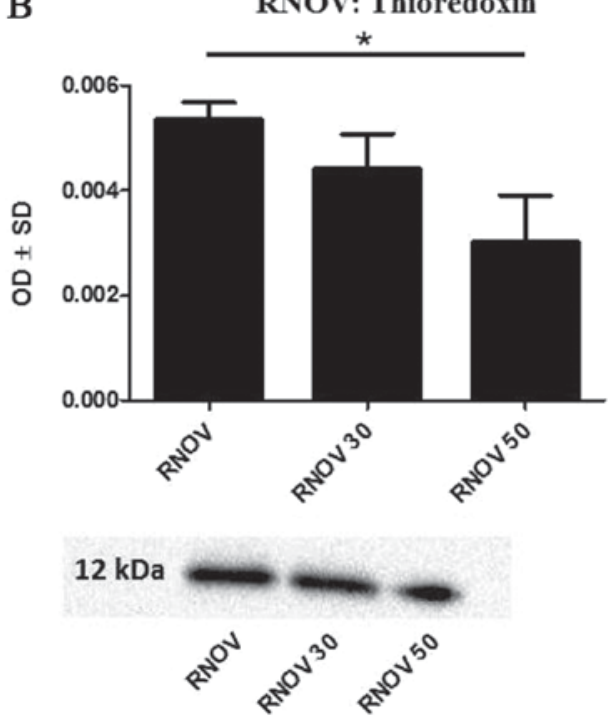

Figure 6. Effect of resveratrol on the expression levels of TXN and TXN in RNOV cell lines. Expression levels of (A) TXN gene and (B) TXN protein in $\mathrm{P}$ and RNOV cell lines. ${ }^{*} \mathrm{P}<0.05,{ }^{* * *} \mathrm{P}<0.001$ and ${ }^{* * * * *} \mathrm{P}<0.0001$. R30, $30 \mu \mathrm{M}$ resveratrol; R50, $50 \mu \mathrm{M}$ resveratrol concentration; $\mathrm{P}, \mathrm{EPG} 85-257 \mathrm{P}$; RNOV, EPG85-257RNOV; TXN, thioredoxin; RQ, relative quantity; OD, optical density; SD, standard deviation.

The present study attempted to demonstrate the effect of resveratrol on the expression of MDR-associated $A B C B 1$, $A N X A 1$ and $T X N$, and the proteins encoded by these genes.

The ability of P-gp to actively remove drugs used for chemotherapy, including DB, results in a low intracellular concentration of these drugs and therefore treatment failure $(14,38)$. The effect of resveratrol was studied in human colorectal cancer HCT116 cell lines that were sensitive or resistant to oxaliplatin (39). In this study, it was revealed that resveratrol treatment results in a reduction in $A B C B 1$ expression in cisplatin-resistant cells in comparison with the expression in cisplatin-sensitive cells, by inhibiting nuclear factor- $\kappa \mathrm{B}$ $(\mathrm{NF}-\kappa \mathrm{B})$ and AMP-activated protein kinase-dependent activation of cAMP response element binding protein. The effect of resveratrol on P-gp expression in the human epidermal carcinoma KBv200 cell line was additionally investigated, and it was demonstrated that resveratrol efficiently reduced the expression of this protein (40). The present study revealed the increased expression of the $A B C B 1$ gene and $\mathrm{P}-\mathrm{gp}$ in the DB-resistant RDB cell line in comparison with a DB-sensitive cell line. Resveratrol significantly reduced P-gp expression at the mRNA and protein level in a concentration-dependent fashion. In the MTX-resistant RNOV cell line, no increased expression of $\mathrm{P}-\mathrm{gp}$ or $A B C B 1$ was observed, indicating that an atypical resistance mechanism was being observed. A previous study demonstrated that, in cancer cells resistant to cytostatics the mechanism of action of curcumin is to inhibit $\mathrm{P}-\mathrm{gp}$ in a competitive or allosteric manner (41).

Until now, to the best of our knowledge, the effect of resveratrol on $A N X A 1$ gene expression in cancer cells remained unstudied. A previous study examined the influence of resveratrol on ANXA1 expression in an acute promyelocytic leukaemia HL-60 cell line, in which it was revealed that the protein level increased depending on the time of incubation with the polyphenol (42). ANXA1 inhibits proliferation and activates apoptosis by affecting the extracellular signal-regulated kinase signaling cascade, binding actin filaments and stimulating cyclin-dependent kinase 2 (43). The main pro-apoptotic mechanism of ANXA1 is most likely via caspase-3 activation $(44,45)$. In addition to the classical MDR mechanism, atypical mechanisms are associated with increased ANXA1 expression in the RDB cell line (46). In the present study, an increase in the expression of ANXA1 in RDB cells compared with that in a DB-sensitive cell line was revealed. Treatment with resveratrol reduced the expression level of ANXA1. However, in MTX-resistant cells, high expression of ANXAl was not observed. At the protein level, treating cells with resveratrol resulted in an increase in ANXA1 expression in DB-resistant cells compared with cells that are DB-sensitive. These results are in line with those obtained by Li et al (42).

The results of studies performed using various types of cancer revealed that $T X N$ gene expression is higher in cancer cells than in non-cancer cells (47). Using two-dimensional gel electrophoresis, TXN expression was observed in an MTX-resistant RNOV cell line (46). The high level of expression of this gene may be associated with increased proliferation, resulting in cancer cell resistance to chemotherapy (48). These results are consistent with those of the present study, which found that TXN is overexpressed in RDB and RNOV cell lines when compared with their expression in drug-sensitive cell lines. Upon incubation of the cells with resveratrol, the level of expression of $T X N$, and that of the protein it encodes, was reduced.

The lowered expression of TXN may induce apoptosis; the key element is the TXN-TXN reductase system, which maintains a proper redox state (49). Deficiency of this protein affects compounds serving notable functions in the cancer transformation process. Amongst the most crucial compounds is the $\mathrm{NF}-\kappa \mathrm{B}$ transcription factor, which is responsible for the transcription of B-cell lymphoma 2 family genes; products of this gene family additionally inhibit apoptosis (49). The decrease in TXN expression results in the inhibition of activation and pro-apoptotic action further apoptosis signal-regulating kinase-1 binding (50). 
In summary, resveratrol is a compound that is able to overcome MDR in human gastric cancer cells. By affecting the expression of genes and proteins that are crucial for MDR, it may contribute to an increase in the efficiency of chemotherapy.

\section{Acknowledgements}

The authors would like to thank Professor H. Lage and Professor M. Dietel (Humboldt University, Berlin, Germany) for providing the EPG85-257 cell lines used in the present study.

\section{References}

1. Tomé-Carneiro J, Larrosa M, González-Sarrías A, Tomás-Barberán FA, García-Conesa MT and Espín JC: Resveratrol and clinical trials: The crossroad from in vitro studies to human evidence. Curr Pharm Des 19: 6064-6093, 2013.

2. Nakata R, Takahashi S and Inoue H: Recent advances in the study on resveratrol. Biol Pharm Bull 35: 273-279, 2012.

3. Gupta C and Prakash D: Phytonutrients as therapeutic agents. J Complement Integr 11: 151-169, 2014

4. Athar M, Back JH, Kopelovich L, Bickers DR and Arianna L: Multiple molecular targets of resveratrol: Anti carcinogenic mechanisms. Arch Biochem Biophys 486: 95-102, 2010.

5. Aguirre L, Fernández-Quintela A, Arias N and Portillo MP Resveratrol: Anti-obesity mechanisms of action. Molecules 19: 18632-18655, 2014.

6. Sinha D, Sarkar N, Biswas J and Bishayee A: Resveratrol for breast cancer prevention and therapy: Preclinical evidence and molecular mechanisms. Semin Cancer Biol 40-41: 209-232, 2016.

7. Rodríguez-Cabo T, Rodríguez I, Ramil M and Cela R Comprehensive evaluation of the photo-transformation routes of trans-resveratrol. J Chromatogr A 1410: 129-139, 2015.

8. Trollope L, Cruickshank DL, Noonan T, Bourne SA, Sorrenti M, Catenacci L and Caira MR: Inclusion of trans-resveratrol in methylated cyclodextrins: Synthesis and solid-state structures. Beilstein J Org Chem 10: 3136-3151, 2014.

9. Lançon A, Michaille JJ and Latruffe N: Effects of dietary phytophenols on the expression of microRNAs involved in mammalian cell homeostasis. J Sci Food Agric 93: 3155-3164, 2013.

10. Jang M,Cai L, Udeani GO, Slowing KV, Thomas CF, Beecher CW, Fong HH, Farnsworth NR, Kinghorn AD, Mehta RG, et al: Cancer chemopreventive activity of resveratrol, a natural product derived from grapes. Science 275: 218-220, 1997.

11. Liu T, Liu X and Li W: Tetrandrine, a Chinese plant-derived alkaloid, is a potential candidate for cancer chemotherapy. Oncotarget 26: 40800-40815, 2016.

12. Gilmore TD and Herscovitch M: Inhibitors of NF-kappaB signaling: 785 and counting. Oncogene 25: 6887-6899, 2006

13. Liu Y, Li Q, Zhou L, Xie N, Nice EC, Zhang H, Huang C and Lei Y: Cancer drug resistance: Redox resetting renders a way. Oncotarget 7: 42740-42761, 2016.

14. Kartal-Yandim M, Adan-Gokbulut A and Baran Y: Molecular mechanisms of drug resistance and its reversal in cancer. Crit Rev Biotechnol 36: 716-726, 2016.

15. Nieth C, Priebsch A, Stege A and Lage H: Modulation of the classical multidrug resistance (MDR) phenotype by RNA interference (RNAi). FEBS Lett 545: 144-150, 2003.

16. Abdallah HM, Al-Abd AM, El-Dine RS and El-Halawany AM: P-glycoprotein inhibitors of natural origin as potential tumor chemo-sensitizers: A review. J Adv Res 6: 45-62, 2015.

17. Wu CP and V Ambudkar S: The pharmacological impact of ATP-binding cassette drug transporters on vemurafenib-based therapy. Acta Pharm Sin B 4: 105-111, 2014.

18. Kapse-Mistry S, Govender T, Srivastava R and Yergeri M: Nanodrug delivery in reversing multidrug resistance in cancer cells. Front Pharmacol 5: 159, 2014.

19. Borska S, Chmielewska M, Wysocka T, Drag-Zalesinska M, Zabel $\mathrm{M}$ and Dziegiel P: In vitro effect of quercetin on human gastric carcinoma: Targeting cancer cells death and MDR. Food Chem Toxicol 50: 3375-3383, 2012.

20. Karthikeyan S, Hoti SL and Prasad NR: Resveratrol modulates expression of $\mathrm{ABC}$ transporters in non-small lung cancer cells: Molecular docking and gene expression studies. Cancer Sci Ther 6: 497-504, 2014.
21. Chen Z, Shi T, Zhang L, Zhu P, Deng M, Huang C, Hu T, Jiang L and Li J: Mammalian drug efflux transporters of the ATP binding cassette $(\mathrm{ABC})$ family in multidrug resistance: A review of the past decade. Cancer Lett 370: 153-164, 2016.

22. Levatić J, Ćurak J, Kralj M, Śmuc T, Osmak M and Supek F Accurate models for P-gp drug recognition induced from a cancer cell line cytotoxicity screen. J Med Chem 56: $5691-5708,2013$

23. Lopes-Rodrigues V, Seca H, Sousa D, Sousa E, Lima RT and Vasconcelos MH: The network of P-glycoprotein and microRNAs interactions. Int J cancer 15135: 253-263, 2014

24. Belvedere R, Bizzarro V, Forte G, Dal Piaz F, Parente L and Petrella A: Annexin A1 contributes to pancreatic cancer cell phenotype, behaviour and metastatic potential independently of Formyl Peptide Receptor pathway. Sci Rep 6: 29660, 2016.

25. Gao Y, Chen Y, Xu D, Wang J and Yu G: Differential expression of ANXA1 in benign human gastrointestinal tissues and cancers. BMC Cancer 14: 520, 2014

26. Wang Y, Serfass L, Roy MO, Wong J, Bonneau AM and Georges E: Annexin-I expression modulates drug resistance in tumor cells. Biochem Biophys Res Commun 314: 565-570, 2004.

27. Powis G, Mustacich D and Coon A: The role of the redox protein thioredoxin in cell growth and cancer. Free Radic Biol Med 29: 312-322, 2000

28. Reuter S, Gupta SC, Park B, Goel A and Aggarwal BB: Epigenetic changes induced by curcumin and other natural compounds. Genes Nutr 6: 93-108, 2011.

29. Borska S, Owczarek M, Pedziwiatr M, Gomulkiewicz A, Pula B and Dziegiel $P$ (unpublished report): In vitro studies of pleiotropic effects of resveratrol on cancer cells resistant to cytostatics. Wisla, 2014.

30. Livak KJ and Schmittgen TD: Analysis of relative gene expression data using real-time quantitative PCR and the 2(-Delta Delta C(T)) method. Methods 25: 402-408, 2001.

31. Laemmli UK: Cleavage of structural proteins during the assembly of the head of bacteriophage T4. Nature 227: 680-685, 1970.

32. Moitra K: Overcoming multidrug resistance in cancer stem cells. Biomed Res Int 2015: 635745, 2015.

33. Kunjachan S, Rychlik B, Storm G, Kiessling F and Lammers T: Multidrug resistance: Physiological principles and nanomedical solutions. Adv Drug Deliv Rev 65: 1852-1865, 2013.

34. Long S, Sousa E, Kijjoa A and Pinto MM: Marine natural products as models to circumvent multidrug resistance. Molecules 21: E892, 2016.

35. Lopes-Rodrigues V, Di Luca A, Sousa D, Seca H, Meleady P, Henry M,Lima RT, O'Connor R and Vasconcelos MH: Multidrug resistant tumour cells shed more microvesicle-like EVs and less exosomes than their drug-sensitive counterpart cells. Biochim Biophys Acta 1860: 618-627, 2016.

36. Borska S, Pedziwiatr M, Danielewicz M, Nowinska K, Pula B, Drag-Zalesinska M, Olbromski M, Gomulkiewicz A and Dziegiel P: Classical and atypical resistance of cancer cells as a target for resveratrol. Oncol Rep 36: 1562-1568, 2016.

37. Lu JJ, Cai YJ and Ding J: The short-time treatment with curcumin sufficiently decreases cell viability, induces apoptosis and copper enhances these effects in multidrug-resistant K562/A02 cells. Mol Cell Biochem 360: 253-260, 2012.

38. Eid SY, El-Readi MZ, Eldin EE, Fatani SH and Wink M: Influence of combinations of digitonin with selected phenolics, terpenoids, and alkaloids on the expression and activity of P-glycoprotein in leukaemia and colon cancer cells. Phytomedicine 21: 47-61, 2013.

39. Wang Z, Zhang L, Ni Z, Sun J, Gao H, Cheng Z, Xu J and Yin P: Resveratrol induces AMPK-dependent MDR1 inhibition in colorectal cancer HCT116/L-OHP cells by preventing activation of NF- $\kappa \mathrm{B}$ signaling and suppressing cAMP-responsive element transcriptional activity. Tumor Biol 36: 9499-9510, 2015.

40. Quan F, Pan C, Ma Q, Zhang S and Yan L: Reversal effect of resveratrol on multidrug resistance in KBv200 cell line. Biomed Pharmacother 62: 622-629, 2008

41. El-Araby ME, Omar AM, Khayat MT, Assiri HA and Al-Abd AM: Molecular mimics of classic p-glycoprotein inhibitors as multidrug resistance suppressors and their synergistic effect on paclitaxel. PLoS One 12: e0168938, 2017

42. Li G, He S, Chang L, Lu H, Zhang H, Zhang H and Chiu J: GADD 45 $\alpha$ and annexin A1 are involved in the apoptosis of HL-60 induced by resveratrol. Phytomedicine 18: 704-709, 2011. 
43. Alldridge LC and Bryant CE: Annexin 1 regulates cell proliferation by disruption of cell morphology and inhibition of cyclin D1 expression through sustained activation of the ERK1/2 MAPK signal. Exp Cell Res 290: 93-107, 2003.

44. Solito E, de Coupade C, Canaider S, Goulding NJ and Perretti M: Transfection of annexin 1 in monocytic cells produces a high degree of spontaneous and stimulated apoptosis associated with caspase-3 activation. Br J Pharmacol 133: 217-228, 2001.

45. Debret R, El Btaouri H, Duca L, Rahman I, Radke S, Haye B, Sallenave JM and Antonicelli F: Annexin A1 processing is associated with caspase-dependent apoptosis in BZR cells. FEBS Lett 546: 195-202, 2003.

46. Sinha P, Hütter G, Köttgen E, Dietel M, Schadendorf D and Lage H: Increased expression of annexin I and thioredoxin detected by two-dimensional gel electrophoresis of drug resistant human stomach cancer cells. J Biochem Biophys Methods 37: 105-116, 1998 .
47. Karlenius TC and Tonnisen KF: Thioredoxin and cancer: A role for thioredoxin in all states of tumor oxygenation. Cancers (Basel) 2: 209-232, 2010.

48. Li C, Thompson MA, Tamayo AT, Zuo Z, Lee J, Vega F, Ford RJ and Pham LV: Over-expression of Thioredoxin-1 mediates growth, survival, and chemoresistance and is a druggable target in diffuse large B-cell lymphoma. Oncotarget 33: 314-326, 2012.

49. Tonissen KF and Di Trapani G: Thioredoxin system inhibitors as mediators of apoptosis for cancer therapy. Mol Nutr Food Res 53: 87-103, 2009.

50. Saitoh M, Nishitoh H, Fujii M, Takeda K, Tobiume K, Sawada Y, Kawabata M, Miyazono K and Ichijo H: Mammalian thioredoxin is a direct inhibitor of apoptosis signal-regulating kinase (ASK) 1. EMBO J 17: 2596-2606, 1998. 